\title{
PODER TECNOLÓGICO E RISCO NA PÓS-MODERNIDADE: REFLEXÕES À LUZ DOS DIREITOS HUMANOS
}

\author{
TECHNOLOGICAL RISK AND POWER IN POST-MODERNITY: \\ REFLECTIONS IN THE LIGHT OF HUMAN RIGHTS
}

\author{
Marcelo Benacchio \\ Doutor e Mestre em Direito pela Pontifícia Universidade Católica de São \\ Paulo. Professor do Mestrado em Direito e Graduação da Universidade Nove \\ de Julho. Professor Titular da Faculdade de Direito de São Bernardo do \\ Campo. Juiz de Direito em São Paulo. E-mail: benamarcelo@gmail.com \\ Queila Rocha Carmona dos Santos \\ Doutoranda em Direito pela Pontifícia Universidade Católica de São Paulo. \\ Mestre em Justiça, Empresa e Sustentabilidade pela Universidade Nove de \\ Julho. Especialista em Direito Tributário. Advogada. E-mail: \\ carmonaqueila@gmail.com
}

Recebido em: 03/03/2015

Aprovado em: 25/02/2016

Doi: $10.5585 /$ rdb.v13i6.245

\begin{abstract}
RESUMO: O tema desta pesquisa é o poder tecnológico e seus potenciais riscos à luz da proteção e preservação dos direitos humanos na pós-modernidade. O objetivo deste estudo é refletir sobre os meios de proteção humana diante do atual cenário de avanço tecnológico. A técnica de pesquisa utilizada é a bibliográfica, sob uma abordagem dedutiva acerca do tema, aderindo à teoria do risco e ao dever de responsabilidade para interpretar o objeto. Diante dessa realidade cumpre haver um diálogo entre tecnologia e direitos humanos com o objetivo de conter os excessos que ameaçam a segurança humana. Em outras palavras, importa ao ordenamento jurídico limitar o poder tecnológico quando este se apresenta ameaçador, ainda que para isso seja necessário uma nova leitura dos direitos já conquistados ou mesmo novas conquistas.
\end{abstract}

Palavras-Chave: Poder Tecnológico; Risco; Pós-Modernidade; Direitos Humanos.

ABSTRACT: This research is an exploration of technological power and its potential risks in relation to the protection and preservation of human rights in postmodernity. The objective of this study is to reflect on the means of human protection given current technological advancement. The research technique used is the literature under a deductive approach on the subject, adhering to the risk theory and the responsibility of duty to interpret the object. Given this reality fulfills be a dialogue between technology and human rights in order to contain the excesses that threaten human security. In other words, it is the law restricting technological power when it presents itself as a threat, even if this new reading of rights already conquered or even new achievements necessary.

Keywords: Technological Power; Risk; Post-Modernity; Human Rights.

INTRODUÇÃO

Revista de Direito Brasileira | São Paulo, SP | v. 13 | n. 6 | p. 231 - 248 | jan./abr. 2016 
A presente pesquisa busca destacar o cenário da tecnologia pós-moderna que, em alguns casos, pode colocar a sociedade em situação de vulnerabilidade por contados riscos inerentes ao ciclo do desenvolvimento.

$\mathrm{O}$ ciclo do desenvolvimento em série de novas tecnologias produz um alerta com relação à falta de conhecimento específico sobre os riscos que podem ser oferecidos por determinadas manipulações tecnológicas.

Portanto, o tema desta pesquisa é o poder tecnológico e seus potenciais riscosà luz da proteção e preservação dos direitos humanos na atualidade.

Diante desse tema, pergunta-se: como a ciência do direito pode atuar para criar limites às manipulações tecnológicas, quando estas se apresentam, ainda que hipoteticamente, nocivas à natureza humana?

A princípio, é possível pensar que o desenvolvimento tecnológico deve ser pautado na observância dos valores consagrados de direitos humanos que buscam concretizar a dignidade da pessoa humana.

O objetivo deste estudo é refletir sobre os meios de proteção humana diante do atual cenário tecnológico. Para tanto, inicia-se pelos conceitos e evolução dos direitos humanos, na sequência busca-se compreender a expressão poder tecnológico com base na teoria do risco. Desse ponto, passa-se a abordar o modelo de sociedade pósmoderna e, por fim, ressalta-se o diálogo entre o poder tecnológico e os direitos humanos.

A presente pesquisa, justifica-se pela importância de aproximar a ciência do direito à realidade contemporânea de acelerado desenvolvimento tecnológico, bem como, em razão da necessária prevalência dos direitos humanos fundamentais em face de ameaças à dignidade humana.

A técnica de pesquisa utilizada é a bibliográfica, sob uma abordagem dedutiva acerca do tema, aderindo à teoria do risco e ao dever de responsabilidadepara interpretar o objeto.

\section{DIREITOS HUMANOS}

Os Direitos Humanos são considerados direitos históricos, conquistados por meio de lutas para afirmação e ampliação dos direitos garantidores do bem estar humano ao longo da história.

No contexto do Estado de Direito a preocupação predominante era com os direitos de liberdade frente o poder do Estado, sendo que, na sequência, as carências percebidas e reivindicações são relativas aos direitos de igualdade. Nessa linha de desenvolvimento social tais exigências adquirem novas razões passando a ser referentes aos direitos de solidariedade na conjuntura do Estado Democrático e Social de Direito.

Essa evolução pode ser compreendida por meio do fenômeno da "dinamogenesis"(SILVEIRA e ROCASOLANO, 2010)dos direitos humanos que consiste no nascimento e desenvolvimento dinâmico do direito de acordo com as necessidades apresentadas em cada momento da história. 
Vladmir Oliveira da Silveira e Maria Mendez Rocasolano(2010, p. 194) compreendem que no mundo axiológico, os valores adquirem novos contornos, que significam a adaptação dos originais às novas particularidades sociais.Portanto, com o desenvolvimento ou nascimento de novos valores em razão das circunstâncias históricas, manifesta-se na sociedade, a necessidade de direitos específicos que protejam tais valores.

Pérez Luño (2010, p. 50)define Direitos Humanos como:

um conjunto de faculdades e instituições que, em cada momento histórico, concretizam as exigências da dignidade, da liberdade e das igualdades humanas, as quais devem ser reconhecidas positivamente pelos ordenamentos jurídicos a nível nacional e internacional. ${ }^{1}$

Segundo o autor, a definição proposta busca unir as grandes dimensões que integram a noção geral dos direitos humanos, ou seja, a exigência jusnaturalista em relação a sua fundamentação e as técnicas de positivação e proteção que possibilitam seu exercício (2010, p. 53).

Vladmir Oliveira da Silveira e Maria Mendez Rocasolano(2010, p. 217) sustentam que o principal fundamento dos direitos humanos é a dignidade da pessoa humana, sendo que, a partir do final da Primeira Guerra Mundial, em 1918, a expressão direitos humanos, vinculou-se ao valor da dignidade da pessoa humana, sob uma concepção de viver, conviver e futuro dos indivíduos dentro da comunidade.

Considerando que os direitos humanos são o resultado de uma evolução ao longo da história, que se deu por meio de lutas para conquistas de direitos, Norberto Bobbio (2004, p. 5) afirma que:

(...) os direitos do homem, por mais fundamentais que sejam, são direitos históricos, ou seja, nascidos em certas circunstâncias, caracterizadas por lutas em defesa de novas liberdades contra velhos poderes, e nascidos de modo gradual, não todos de uma vez e nem de uma vez por todas.

Portanto, pode-se considerar que os direitos humanos foram afirmados, aos poucos, de acordo com as carências humanas de proteção frente ao poder.

Nessa linha, houve a princípio a conquista de direitos individuais relacionados aos valores de liberdade. Em um segundo momento se reconhece que esses direitos não são suficientes para assegurar a dignidade da pessoa humana, assim, ocorre à complementação com os direitos coletivos fundados no valor da igualdade. Após tais conquistas, a sociedade em constante evolução se modifica passando a ter novas carências de direitos, dos quais, se destacam o direito ao desenvolvimento e ao meio ambiente, inclusive para as futuras gerações, sob a perspectiva do valor de solidariedade.

Importa, pois destacar a teoria do poder como basilar à formação dos direitos humanos. Vladmir Oliveira da Silveira e Maria Mendez Rocasolano(2010, pp. 2122)argumentam que:

O desenvolvimento da noção de direitos humanos configura uma história de confrontação e de luta incessante pelos valores da humanidade, em que o poder imposto aos homens e sua organização em comunidades, povos e

\footnotetext{
${ }^{1}$ Tradução nossa (un conjunto de facultades e instituciones que, en cada momento histórico, concretanlasexigencias de ladignidad, lalibertad y laigualdad humanas, lascualesdeben ser reconocidas positivamente por losordenamientos jurídicos a nivel nacional e internacional).
} 
Estados, foi se perdendo nas batalhas sob a ordem da liberdade, igualdade e solidariedade (fraternidade) dos seres humanos, que se rebelaram guiados pelas luzes da razão e dos valores e sentimentos compartilhados.

Esses movimentos de lutas para o reconhecimento e proteção de direitos inerentes à dignidade da pessoa humana surgiram contra poderes que operavam de modo vertical, em desfavor da sociedade e até mesmo da humanidade. Tratava-se da imposição da vontade arbitrária daqueles que detinham o poder sobre a coletividade.

Desta feita, os direitos humanos nascem para tutelar as necessidades humanas em uma dimensão não apenas individual, mas também coletiva relacionada ao bem comum. Esses direitos, entendidos como inerentes ao homem passam a ser positivados em declarações universais e regionais de direitos, bem como, em âmbito interno, nas constituições estatais.

Para Norberto Bobbio(2004, p. 203) “o reconhecimento e a proteção dos direitos do homem são a base das constituições democráticas". Portanto, os direitos humanos passam, de forma crescente, a fazer parte das constituiçõescomo resultado do reconhecimento desses direitos no âmbito dos Estados.

O autor sustenta que a Declaração Universal de Direitos Humanos é apenas o início de um longo processo de desenvolvimento dos direitos humanos, pois "os direitos do homem nascem como direitos naturais universais, desenvolvem-se como direitos positivos particulares, para finalmente encontrarem sua plena realização como direitos positivos universais"(2004, p. 30).

Os direitos humanos têm suas origens ligadas ao direito natural do homem e ao se desenvolverem no decorrer da história, tornam-se direito positivado, tanto em escala universal quanto estatal. Destaca-se, no entanto, que a universalidade ${ }^{2}$ dos direitos humanos no âmbito do multiculturalismo estatal pode sofrer diferentes interpretações, mas ainda que as culturas se diferenciem a essencialidade e natureza desses direitos não mudam, pois, em suma, são voltados à proteção da vida, liberdade, igualdade e dignidade da pessoa humana.

Nesse sentido argumenta Norberto Bobbio (2004, p. 28) que após a Declaração Universal é possível ter a certeza histórica de que "toda a humanidade partilha alguns valores comuns; e podemos, finalmente, crer na universalidade dos valores".

A Declaração Universal de Direitos Humanos é o documento que introduz a positivação dos direitos humanos. Essa declaração é considerada a mais importante, pois dela surgem as demais declarações internacionais de direitos do homem, nas esferas universal e regional. Assim, a partir desse marco inicial, as constituições em âmbito estatal passam também a reconhecer e positivar os direitos humanos.

Conforme Isabel Cabrita (2011, p. 47), a compreensão de pessoa humana fundante do movimento internacional dos Direitos Humanos é uma concepção normativa e política não podendo ser confundida em outras visões do ser humano, a

\footnotetext{
${ }^{2}$ Flávia Piovesan argumenta que o ponto de partida dos relativistas é o coletivismo, sendo que o indivíduo é percebido apenas como parte integrante da sociedade. Diversamente, sob a ótica dos universalistas, o primado é o individualismo, portanto, o ponto de partida é o indivíduo, sua liberdade e autonomia, para então se chegar à coletividade. Sustenta ainda que "os instrumentos internacionais de direitos humanos são claramente universalistas, uma vez que buscam assegurar a proteção universal dos direitos e liberdades fundamentais (...) para os universalistas o fundamento dos direitos humanos é a dignidade humana, como valor intrínseco à própria condição humana" (2012, pp. 216-218).
} 
exemplo das definidas pela biologia, psicologia ou ciências sociais. Portanto, os Direitos Humanos são direitos na acepção jurídica.

O reconhecimento e positivação dos direitos humanos nas constituições dos Estados pode ser entendido como movimento de constitucionalismo dos direitos humanos, ou seja, positivam-se esses direitos a partir de um exercício mútuo de constitucionalização dos diretos humanos e internacionalização dos direitos fundamentais.

Os direitos fundamentais são um conjunto de direitos e garantias previstos nas constituições que devem ser interpretados e refletidos em todo o ordenamento jurídico infraconstitucional.

Robert Alexy (2012, p. 520) sustenta que o significado das normas de direitos fundamentais resulta de dois fatores: a fundamentalidade formal e a fundamentalidade substancial.

A partir das teses das fundamentalidades formal e substancial compreende-se que as normas de direitos fundamentais exercem o papel principal no cenário do sistema jurídico, pois ocupam o topo do ordenamento jurídico interno e, nessa posição de destaque se tornam fonte obrigatória para a criação das demais normas, vinculando assim, a formação da base normativa estatal, bem como, a atuação dos três poderes.

Fábio Konder Comparato (2007, p. 227) afirma que "distingue os direitos humanos dos direitos fundamentais, na medida em que estes últimos são justamente os direitos humanos consagrados pelo Estado mediante normas escritas".

Dessa forma, os direitos e garantias fundamentais positivados constitucionalmente devem promover em âmbito interno a prevalência da dignidade da pessoa humana, como parte de sua responsabilidade perante a ordem internacional, pois paralelo ao ordenamento jurídico nacional há os sistemas de proteção universal e regional que atuam como poder subsidiário à atuação estatal para assegurar a observância dos direitos humanos fundamentais.

Pérez Luño(2010, p. 219) ao tratar das noções de direitos fundamentais e Estado de Direito ressalta que "os direitos fundamentais representam, por sua vez, os princípios inspiradores de toda a política estatal. Pelo que cumprem uma missão de fundamento e limite de todas as normas que organizam o funcionamento dos poderes públicos" (...). ${ }^{3}$

No entanto, em termos de políticas estatais e de ordenamento jurídico é possível citar o ocorrido na Alemanha no III Reich - período em que nasceu e se desenvolveu o nazismo. Robert Alexy e Alfonso García Figueroa (2007, p. 81) apontam que "as normas extremamente injustas do III Reich não são Direito. Nem todas as leis escritas são Direito. O conteúdo do Direito excede o das leis propriamente positivas". 4

Importa o contexto da Alemanha nazista para ilustrar que a violência histórica praticada por esse regime contra a dignidade humana estava toda baseada em leis

\footnotetext{
${ }^{3}$ Tradução nossa(losderechosfundamentalesencarnan, a su vez, losprincipios inspiradores de toda la politica estatal. Por lo que cumplen una misión de fundamento y límite de todas las normas que organizanelfuncionamiento de los poderes públicos).

${ }^{4}$ Tradução nossa (las normas extremadamente injustas del III Reich no sonDerecho. No todas lasleyes escritas sonDerecho. El contenidodelderecho excede el de lasleyespropiamente positivas).
} 
internas, mas, todavia, se tratavam de leis injustas e violadoras dos direitos naturais e humanos de vida, liberdade e igualdade.

Destarte, os direitos fundamentais cumprem com as funções de fundamento e limite às demais normas e às políticas estatais, sendo que, no atual cenário do Estado Democrático e Social de Direito, de forma mais ampla, os direitos fundamentais vinculam também as diretrizes na esfera particular, sob uma perspectiva de solidariedade, pois moldam as tomadas de decisões de acordo com as obrigações e responsabilidades perante o ordenamento jurídico vigente.

Robert Alexy(2012, pp. 524-528) afirma que atualmente as normas de direitos fundamentais produzem efeitos na relação cidadão/cidadão, pois influenciam essa relação e geram efeitos horizontais perante terceiros. Ainda, o autor ressalta que a relação Estado/cidadão se dá entre um titular de direitos fundamentais e um não titular. De outro modo, a relação cidadão/cidadão é uma relação entre titulares de direitos fundamentais(2012, p. 528).

$\mathrm{O}$ autor destaca no tocante aos direitos fundamentais e a natureza do sistema jurídico que as normas de direitos fundamentais propagam efeitos em todos os ramos do direito. O primeiro efeito que pode ser citado é a limitação do conteúdo do direito ordinário, de modo que o sistema jurídico é substancialmente determinado pela Constituição. Já o segundo efeito reflete na natureza principio lógica das normas de direitos fundamentais, ou seja, tais normas são consideradas como princípios e, desse modo, exigem o processo de sopesamento em caso de conflito, para chegar à solução mais adequada. Por fim, o terceiro efeito a ser considerado é a abertura do sistema jurídico frente à moral, tendo em vista os conceitos básicos de direitos fundamentais, conceitos de dignidade, liberdade e de igualdade. Assim, o reflexo dos direitos fundamentais positivados em todos os ramos do direito resulta na ideia de justiça em todas essas áreas (2012, pp. 543-544).

Portanto, diante de tais considerações importa ressaltar os preceitos de direitos fundamentais da Constituição Federal de 1988 que fundamentam juridicamente a proteção e bem estar da sociedade e dão base às reflexões da presente pesquisa no que se refere aos riscos das inovações tecnológicas e a necessidade de aproximação da ciência do direito ao atual contexto histórico.

$\mathrm{O}$ artigo $1^{\mathrm{o}}$, inciso III, da Constituição Federal introduz a dignidade da pessoa humana como princípio fundamental do Estado, nos seguintes termos: "A República Federativa do Brasil, formada pela união indissolúvel dos Estados e Municípios e do Distrito Federal, constitui-se em Estado Democrático de Direito e tem como fundamentos:(...) III - a dignidade da pessoa humana".

Nessa linha de proteção da dignidade da pessoa humana, a Constituição Federal ao estabelecer os direitos e garantias fundamentais, prevê no artigo $5^{\circ}$, entre as demais previsões, a inviolabilidade dos direitos à vida, liberdade, igualdade e segurança.

Assim sendo, pode-se afirmar que o ordenamento jurídico interno tem como princípio básico a proteção da dignidade da pessoa humana de acordo com as diretrizes dos sistemas protetivos universal e regionais. $\mathrm{O}$ sentido de proteção constitucional possibilita, ainda, a ampliação da proteção e criação de novos direitos como é o caso do artigo $5^{\circ}$, parágrafo $2^{\circ}$, entendido como clausula de abertura. No entanto, a grande dificuldade é sempre como dar efetividade aos preceitos que visam à proteção humana, sendo certo, que para fortalecimento dessa proteção é essencial a 
complementação entre o direito interno e o direito internacional de proteção dos direitos humanos fundamentais.

\section{PODER TECNOLÓGICO E A TEORIA DO RISCO}

Os tempos atuais são dominados pela tecnologia, tecnologia é poder. Quem domina a tecnologia tem poder sobre as pessoas por possibilitar controle da sociedade numa perspectiva nunca antes vista pela humanidade.

O poder tecnológico pode ser dominado tanto pelos Estados como pelas empresas, exigindo pronta atuação no sentido da possibilidade de acesso a todos e mesmo defesa com relação às novas formas de controle e vigilância dos seres humanos.

Quem domina a tecnologia pode viver mais, conhecer mais e, noutra quadra, dominar as pessoas, portanto, é imprescindível ordenar o poder tecnológico pelo Direito.

Precisas são as considerações de C.G. Weeramantry (2003, p. 307) referente ao poder tecnológico nas mãos das empresas, conforme segue:

O desenvolvimento da tecnologia corre em paralelo com o crescimento dos impérios empresariais dela detentores. Porque a tecnologia sofisticada é cara e porque sua geração e seu controle demandam vultosos investimentos, as grandes corporações empresariais costumam ter sua propriedade. Essas corporações - cujo poder financeiro, em muitos casos, supera o de diversos países — dão à tecnologia uma potência adicional: a combinação das forças econômica e tecnológica. Juntas, estas representam uma falange de poder que está bem acima da capacidade de resistência do indivíduo.

O acelerado desenvolvimento tecnológico é um fenômeno inerente ao atual período histórico. É possível lidar com as facilidades proporcionadas por esse desenvolvimento, como por exemplo, a redução de distância e tempo para locomoção e comunicação, a diminuição considerável dos aparelhos eletrônicos com aumento de suas funções e capacidade de armazenamento de dados.

Vale ressaltar ainda, os avanços nas pesquisas científicas que trouxeram novas possibilidades de aplicações industriais, tratamento de doenças, diagnósticos, aumento da qualidade e estimativa de vida, bem como, a manipulação genética que permite ao homem modificar sua própria natureza, entre outros avanços das últimas décadas.

Em termos de tecnologia, Francesco di Ciommo(2003) afirma que houve primeiro a evolução da técnica para se chegar ao desenvolvimento da tecnologia. A técnica, a princípio, era o instrumento essencial para a sobrevivência do homem, sendo que, o homem era o sujeito manipulador da técnica. Para o autor "a técnica, de instrumento a disposição do homem, tornou-se assim o seu ambiente; de meio para satisfazer as suas exigências naturais, tornou-se, em alguns aspectos, produto e, por outros, fonte de sempre novas necessidades e problemas" (2003, p. 16). ${ }^{5}$

\footnotetext{
${ }^{5}$ Traduçãonossa (La tecnica, da strumento a disposizione dell'uomo, è così diventata il suo ambiente; da mezzo per soddisfare le sue esigenze naturali, è diventata, per certi versi, prodotto e, per altri, fonte di sempre nuovi bisogni e problemi).
} 
Segundo explicação do autor (a partir da definição do vocabulário italiano), a palavra técnica se traduz como o conjunto de normas que regulam o concreto desenvolvimento de uma atividade manual ou intelectual ou como qualquer forma de atividade humana voltada ao conhecimento da ciência e à criação de novos produtos e instrumentos que melhoram as condições de vida humana (2003, p. 17).

Com base nessa definição, pode-se entender que técnica era o método para o homem desempenhar seu trabalho, ou seja, o caminho para chegar a determinado fim. No entanto, com a evolução tanto da ciência quanto da técnica chega-se à tecnologia que, por sua vez, passa a ocupar o lugar de destaque da técnica, agora também como fim.

Desta feita, a lógica se inverte, pois o objeto passa a manipular o sujeito. Nesse sentido, aponta Francesco Di Ciommo(2003, p. 17) que a tecnologia e não mais a atividade humana preside a sua própria criação ao ditar os ritmos e dimensões do desenvolvimento tecnológico futuro e, em última análise, da própria existência do indivíduo.

O significado da técnica, enquanto instrumentação nas mãos do homem para satisfazer suas necessidades naturais, era completamente absorvido pelo fim específico a que esta era destinada a perseguir. Todavia, o aumento quantitativo e imensurável da tecnologia na atualidade, possibilita o alcance de qualquer fim, o que faz mudar qualitativamente o cenário, pois não é mais o fim ético ou prático a condicionar a pesquisa científica, mas sim os resultados da pesquisa a condicionar os fins (CIOMMO, 2003, p. 18).

Portanto, de forma concisa, o autor entende que nesta era, a tecnologia produz sempre novos resultados universalmente aplicáveis, o que a torna autorreferencial e independente. Destarte, não existem valores, ideologias, nem ética, capazes de condicionar a tecnologia, uma vez que, esta nega qualquer tradição e, em seu rápido avanço se coloca como elemento de ruptura com o cenário preexistente, queimando etapas e alcançando objetivos que muitas vezes a ciência não visa (2003, p. 20).

Tendo em vista que a técnica deixa de ser mero instrumento para ser o próprio fim tecnológico, esta, passa a provocar efeitos positivos e negativos na vida em sociedade. Nicolau Sevcenko (2001, p. 18), no entanto, aponta que a técnica "é socialmente consequente quando dialoga com a crítica. O problema, assim, não é nem a técnica e nem a crítica, mas a síndrome do loop, que emudece a voz da crítica, tornando a técnica surda à sociedade".

Dessa forma, ainda que a tecnologia ordene seu próprio desenvolvimento, em uma perspectiva de fim, limites devem ser criados no campo científico.Os limites de atuação tomam maior relevância diante de novas tecnologias que envolvem riscos como,por exemplo, as nanotecnologias que lidam com manipulações de partículas muito pequenas e a biotecnologia que está relacionada à manipulação de organismos vivos.

De outra parte, para abordar a questão da responsabilidade acerca da produção do risco, cumpre refletir sobre o tema do ponto de vista da teoria de Ulrich Beck.

Consoante a teoria do risco, entende-se que a humanidade vive sob as ameaças dos riscos gerados pela própria ação humana, pois, na chamada sociedade reflexiva ou de risco, produz-se ou permite-se a produção daquilo que possivelmente será uma ameaça. Com relação à crítica e reflexividade do desenvolvimento científicotecnológico, UlrichBeck (2010, p. 236)afirma que: 
as ciências são confrontadas tanto com o balanço de seus êxitos quanto com o balanço de seus fracassos e, portanto, com o reflexo de suas promessas descumpridas. São muitas as razões por trás disto: justamente com seus êxitos, parecem crescer desproporcionalmente também os riscos da evolução técnico-científica; soluções e promessas libertadoras, quando realizadas na prática, acabam por revelar inegavelmente seu lado problemático, que se converte, por sua vez, em objeto de intensivas análises científicas;

Pode-se compreender, conforme o pensamento do autor, que os resultados do avanço científico-tecnológico são confrontados em relação à proporcionalidade de êxitos e fracassos, os fracassos podem ser inseridos na esfera do risco, muitas vezes nãocalculado pelos cientistas.

O autor ainda faz uma comparação interessante, contrapondo-se à ideia de que o risco é necessário para a evolução. Assim expõe que, quando Colombo saia em busca de terras e novos continentes, assumia diversos riscos. No entanto, esses riscos eram pessoais e não globais como os que se apresentam atualmente. Desse modo, "a palavra 'risco' tinha, no contexto daquela época, um tom de ousadia e aventura, e não o da possível autodestruição da vida na Terra"(2010, p. 25).

Destarte, os riscos assumem uma nova importância a partir do atual contexto histórico de desenvolvimento.

A sociedade está mais exposta aos riscos desconhecidos e potencialmente desprotegida com relação ao futuro por conta, também, do rompimento com a tradição, comum na atualidade.

A humanidade atravessa uma era tecnológica repleta de mudanças em diversas áreas, entretanto, muitos dos novos resultados correspondem à inovações pouco exploradas ou conhecidas no que se refere aos efeitos colaterais e riscos. Sob essa ótica, o ponto de chegada, ou seja, o futuro se torna um tanto imprevisível.

Diante disso cumpre à ciência jurídica, por meio das diretrizes de Direitos Humanos, se ocupar com os riscos tecnológicos que podem ser uma ameaça a humanidade, buscando prevenir e com isso afastar a ocorrência de possíveis danos iminentes ou futuros.

Os riscos tecnológicos colocam a humanidade em situação de vulnerabilidade, frente aos efeitos em cadeia, bons e ruins, do desenvolvimento. A humanidade não poderá reagir aos maus efeitos se tais não forem antecipados com prudência, conforme o entendimento de Nicolau Sevcenko (2001), enquanto a humanidade estiver presa aos movimentos desenfreados, equivalentes a uma montanha-russa, não será possível resistir ao loop, que em tese, é o movimento que causa mais insegurança e medo.

Tendo em vista a complexidade dos riscos, Nicolau Sevcenko(2001, pp. 100101) alerta que:

(...) não se trata de condenar pura e simplesmente cientistas e técnicos por falta de responsabilidade, mas de entender como funcionam as políticas que controlam as decisões sobre as pesquisas e os processos produtivos. Nesse sentido e ao mesmo tempo, é necessário pressionar pela definição de práticas científicas que estejam atentas às incertezas presentes nos sistemas complexos e, portanto, que considerem seriamente os limites dentro dos quais se dá a produção dos conhecimentos. Essas seriam as condições necessárias para o estabelecimento de um tipo de ciência dotado de alto

Revista de Direito Brasileira | São Paulo, SP | v. 13 | n. 6 | p. 231 - 248 | jan./abr. 2016 
senso de responsabilidade e alerta para a vulnerabilidade e as peculiaridades do meio ambiente e dos seres humanos.

Dessa forma, mecanismos de regulação de risco devem ser criados por meio do diálogo entre técnica e crítica a fim de se estabelecer um conceito de tecnologia com "alto senso de responsabilidade e alerta para a vulnerabilidade" humana e do meio ambiente.

Nicolau Sevcenko(2001, pp. 17-18) afirma que "a crítica, portanto, é a contrapartida cultural diante da técnica, é o modo de a sociedade dialogar com as inovações, ponderando sobre seu impacto, avaliando seus efeitos e perscrutando seus desdobramentos".

O autor explica ainda que, a palavra crítica vem do grego e significa 'decidir' ou seu equivalente em latim 'discernir'. Para o autor, neste momento em que as rápidas mudanças vem sufocando a reflexão e o diálogo, é necessário uma estratégia orientadora da crítica que se divide em três movimentos essenciais: i) desprender-se do ritmo acelerado das mudanças atuais para obter um distanciamento que permita um discernimento crítico; ii) recuperar o tempo da própria sociedade, ou seja, a história,a fim de verificar a natureza, a dinâmica e os efeitos das mudanças em curso; iii) sondar o futuro a partir da crítica colocando a técnica a serviço de valores humanos(2001, pp. 18-19).

Por meio da crítica, a sociedade pode tomar conhecimento das inovações tecnológicas, bem como, de seus riscos. Partindo desse ideal, é possível projetar um desenvolvimento pautado em equilíbrio e segurança para garantir o bem estar das gerações atual e futura.

Em termos de risco,Teresa Ancona Lopez(2010, p. 103) entende como um importante instrumento para se evitar danos à sociedade o princípio da precaução:

aquele que trata das diretrizes e valores do sistema de antecipação de riscos hipotéticos, coletivos ou individuais, que estão a ameaçar a sociedade ou seus membros com danos graves e irreversíveis e sobre os quais não há certeza científica; esse princípio exige a tomada de medidas drásticas e eficazes com o fito de antecipar o risco suposto e possível, mesmo diante da incerteza.

Conforme o conceito da autora os riscos podem ser antecipados por meio de dois princípios: o princípio da prevenção e o princípio da precaução. O princípio da prevenção é voltado para casos em que os riscos são determinados, de outra parte, o princípio da precaução é aplicado quando os riscos sãoindeterminados.

O risco tem uma existência incerta, potencial, duvidosa, podendo ser existente e não existente, presente e não presente e suposto em todas atividades tecnológicas. Por isso é fundamental sua prevenção e precaução por meio de cálculos de sua antecipação permitindo a proteção da sociedade para sua eventual ocorrência; notadamente os riscos globais que aproximam os presentes e ausentes, próximos e distantes em uma nova perspectiva de um complexo espaço moral e político de responsabilidade (BECK, 2008, p. 256) de todos por todos.

\section{PÓS-MODERNIDADE}


O método é a estrutura metodológica da modernidade na busca de uma verdade incontroversa, eterna e imutável. A razão estabelece a ruptura com a tradição e o dogma da fé na busca de uma verdade objetiva, inabalável.

O conhecimento científico da modernidade apoiado na razão garante a certeza do resultado afastando a dúvida existente antes da utilização das certificações racionais.

Nessa perspectiva, o Direito da modernidade,autônomo e autofundado, considera-se válido de maneira indiferentemente ao seu conteúdo, evitando qualquer influência da política e da religião, afirmando-se abstrato e geral como meio de neutralizar os conteúdos (BARCELLONA, 2003, p. 49).

O método racional da modernidade permite construções infinitas e amplas, para Boaventura de Souza Santos (2010, p. 78) essa complexidade repercute na impossibilidade de acomodar valores que são apenas abstratamente compatíveis, conforme segue:

Mas é fácil ver que um horizonte tão excessivo contém, em si mesmo, o gérmen de um défice irreparável. Por um lado, a construção abstracta dos pilares confere a cada um deles uma aspiração de infinitude, uma vocação maximalista, quer seja a máxima regulação ou a máxima emancipação, que torna problemáticas, se não mesmo impensáveis, estratégias de compatibilização entre eles, as quais necessariamente terão de ser assentes em cedências mútuas e compromissos pragmáticos.

As dificuldades da solução dos problemas humanos pelo paradigma da modernidade na crença de valores universais deduzidos pela racionalidade e a dificuldade, senão impossibilidade, da construção de uma sociedade universal sem influências de contextos locais e centrada no Estado, redundaram em diversas críticas à modernidade, culminando com o pós-modernismo enquanto reação a essa tendência totalizante.

O pós-modernismo não acredita na razão, na abstração e na generalidade como forma de solução das questões humanas, buscando outros elementos no sentido da desconstrução racional e comunicação entre a diferença e a pluralidade.

António Manuel Hespanha (2012, p. 560) trata da oposição entre modernidade e pós-modernidade da seguinte forma:

A reação pós-modernista dirige-se contra tudo isto. Ao geral opõe o particular; ao gigantismo do "grande" opõe a beleza do "pequeno" (smallisbeautiful); à eficácia da perspectiva macro opõe a delicada subtileza da perspectiva micro; ao sistema opõe o "caso"; ao ativismo projetual opõe a indolência contemplativa; à heterorregulação, a autorregulação; ao funcional opõe o lúdico; ao objetivo opõe o subjetivo; à "verdade" opõe a "política" (o "testemunho", "o compromisso").

Na pós-modernidade o modelo de solução passa ao caso concreto em diálogo com o sistema incidente, há uma ampliação da compreensão jurídica para abarcar e acomodar a pluralidade existente.

Nessa perspectiva, Zagrebelsky (2010, p. 203) amplia o Direito (da modernidade) para os direitos, a justiça e a lei adequadas ao caso concreto a partir da 
compreensão de quem atua juridicamente para chegar na aplicação mais razoável frente as circunstâncias existentes na consecução da "ragionevolezza".

Desse modo, o atual modelo de sociedade da chamada pós-modernidade, é caracterizado pela leveza das estruturas econômicas, sociais e das relações humanas, pois a exigência do momento é a eficiência e mobilidade. Nessa linha, prevalece também o individualismo e a busca incessante pelos fins independentemente dos meios. Essa realidade, portanto, dificulta a criação do diálogo entre técnica e crítica como um meio para projetar o futuro tecnológico.

Cumpre considerar que os avanços tecnológicos não trazem apenas benefícios, mas também efeitos adversos que em muitos casos são de difícil identificação.

O passado, as experiências históricas, a luta para conquista e afirmação de direitos humanos, não devem ser desprezados em face da plenitude das novidades e mudanças do presente, sob pena do futuro ser o reflexo de um período de inconsequência na história da humanidade.

Evidencia-se na pós-modernidade uma inversão de valores nos âmbitos particular e coletivo, mas especialmente em relação às questões de mercado, consumo e tecnologia. Na era da técnica buscava-se por meio da pesquisa alcançar um fim ético para o bem do homem. De modo inverso, na era da tecnologia o valor ético se perde diante das intermináveis novas possibilidades e criações.

Pietro Barcellona (2005, p. 131), diante dos traços da atualidade, defende que o individualismo narcisista do consumo não tem e não confere identidade e sua lógica é a da autorreferência, ou seja, é a lógica do sistema imunológico - não comunicativa e sim defensiva, pois se defende da penetração da doença por meio da produção de anticorpos e utiliza apenas o que precisa para se conservar.

Dessa forma, o indivíduo, no auge do narcisismo, tem como referência a si mesmo, fechando-se ao mundo exterior, às percepções externas, abrindo-se apenas para aquilo que lhe interessa e que poderá trazer algum benefício instantâneo.

ZygmuntBauman(2001, p. 39) considera que a marca registrada da modernidade líquida é a apresentação dos membros da sociedade como indivíduos.

Tal característica, entretanto, faz com que os membros da sociedade se tornem indiferentes ao bem comum, pois a grande preocupação está relacionada consigo mesmo e não com o próximo.

O autor ainda aponta que "no mundo dos indivíduos há apenas outros indivíduos cujo exemplo seguir na condução das tarefas da própria vida, assumindo toda a responsabilidade pelas consequências de ter investido a confiança nesse e não em qualquer outro exemplo"(2001, p. 39).

Consequentemente, é possível entender que,na atualidade os indivíduos buscam ter o outro como modelo ou referência de vida, o que se traduz na perda de identidade ou dos próprios valores.

No mesmo sentido, Gilles Lipovetsky(2013, p. 82) aponta o narcisismo como a característica inaugural dos tempos pós-moderno ${ }^{6}$, com base nesse entendimento salienta que "o narcisismo designa a emergência de um perfil inédito do indivíduo

\footnotetext{
${ }^{6}$ Vale citar que o autor utiliza na obra consultada a expressão pós-modernidade, todavia, em outras obras faz referência a expressão hipermodernidade por entender que retrata de forma mais ampla e fiel as características da sociedade contemporânea.
}

Revista de Direito Brasileira | São Paulo, SP | v. 13 | n. 6 | p. 231 - 248 | jan./abr. 2016 
nas suas relações consigo e com o seu corpo, com outrem, com o mundo e com o tempo".

$\mathrm{O}$ autor entende a pós-modernidade como um período de individualismo ao extremo, em que as relações do indivíduo com o mundo exterior se dão de modo narcisista, predominando os interesses puramente pessoais, desembaraçados de valores sociais ou morais da era moderna.

Portanto, pode-se entender que o individualismo predominante nesta eraobscurece a assimilação da realidadee do todo no que se refere as potenciais ameaças à segurança humanano âmbito coletivo. Por essa razão o valor consagrado e basilar para proteção da dignidade da pessoa humana,na atual geração de Direitos Humanos, é a solidariedade.

Desta feita, convém ainda citar a interpretação do conceito de sociedade do risco de Ulrich Beck, destacada por Marcos Antônio Mattedi (2002, p. 141), conforme adiante:

Enquanto a sociedade industrial, que marcou o processo de modernização simples, organizava-se através de uma lógica positiva fundamentada na possibilidade de distribuição da riqueza, a sociedade do risco, que caracteriza o processo de modernização reflexiva, organiza-se com base numa lógica negativa de distribuição do risco, pois, segundo o autor, no estágio de modernização reflexiva a produção social da riqueza é indissociável da produção social do risco. Além disso, a lógica positiva contrasta com a lógica negativa porque a riqueza tende a ser concentrada no topo da sociedade através da apropriação política por poucos grupos sociais, e, ao contrário, o risco é dispersado na base por toda a sociedade: estabelece-se uma afinidade estrutural entre pobreza extrema e risco extremo.

De acordo com a lógica de distribuição do risco na sociedade pós-moderna, é possível compreender que a produção de riqueza resulta na produção do risco. Dessa forma, tal dinâmica faz com que o risco se concentre na base da sociedade enquanto a riqueza se mantém no topo.Logo, os atores sociais que ocupam a base da sociedade suportam além da pobreza também os riscos.

UlrichBeck (2010, p. 30) ressalta um déficit do "pensamento social", em relação aos problemas que afetam direta ou indiretamente o bem estar humano e que surgem originalmente nas sociedades altamente desenvolvidas.

O déficit do "pensamento social"se dápelo individualismo ao extremo que resulta no afastamento dos valores essenciais de proteção dos Direitos Humanos diante dos interesses de cunho econômico. Por conseguinte, prevalecem na atualidade os valores egoísticos sobre o ânimo de cooperação para o bem comum. 


\section{A TECNOLOGIA E OS DIREITOS HUMANOS}

O incremento e a criação de novas tecnologias a partir do final do século XX e seu aumento exponencial neste início de século repercutiram na modificação da forma de compreender e de viver das pessoas em todo planeta.

A revolução tecnológica reformulou as relações do ser humano com os demais seres humanos, as relações entre o ser humano e a natureza, bem como as relações do ser humano para consigo mesmo, afetando diretamente as esferas dos direitos e liberdades (PÉREZ LUÑO, 2014, p. 18).

As novas tecnologias da informação e da comunicação conduziram a humanidade para um novo patamar, revelando a insuficiência da solução dos novos desafios pela projeção do passado ao futuro em conformidade à compreensão iluminista da codificação do Direito.

Há várias situações sem paralelo no passado, a exemplo da engenharia genética e tantas outras situações semelhantes reveladoras das dificuldades do Direito em apresentar um paradigma adequado e seguro de solução. modernidade.

Conforme exposto, a pós-modernidade não permite as "certezas" da

Assim, a aplicação da tecnologia no âmbito da reprodução assistida, com a maternidade de substituição, tornou incerta a antes indiscutível máxima romana matersemper certa est, pater autem incertus -ante a possibilidade de não coincidência entre a gestação e a filiação nessa hipótese.

A tecnologia implica na criação de armas de destruição em massa e violação da privacidade por meio de máquinas presentes anteriormente apenas no campo da ficção; inclusive reforçando o poder de governos e empresas no acompanhamento dos comportamentos e pensamentos dos seres humanos.

A rede mundial de computadores aproximou regiões remotas e permitiu influências sem a necessidade de invasão territorial física de uma nação a outra; além disso, houve a formação do poder privado em acréscimo à soberania estatal.

Desse modo, o desafio da atualidade é a compatibilização entre os aprendizados do passado que repercutiram na Declaração Universal dos Direitos Humanos e o futuro acerca da evolução da proteção internacional dos Direitos Humanos (LAUREN, 2003, p. 281), porquanto a sociedade pós-industrial a partir doseu conjunto de tecnologias revolucionárias nos obriga a repensar a condição humana (DONAS, 2012, p. 13).

A tecnologia afetou os direitos humanos em sua totalidade e na complexidade de sua evolução, cabendo uma compreensão ampliada da Declaração Universal dos Direitos Humanos de 1948.

Dessaforma, as novas tecnologias vão repercutir nos direitos humanos de liberdade por permitirem novas maneira de manifestação do pensamento, nos direitos humanos sociais no sentido da possibilidade de acesso a todos à tecnologia, nos direitos de solidariedade no aspecto dos direitos coletivos e na aproximação do norte e do sul na realização da condição humana. 
Javier Bustamante Donas (2012, p. 17) sustenta que as novas tecnologias criaram os direitos humanos de quarta geração no sentido da expansão de um conceito de cidadania digital que apresenta várias dimensões. São suas proposições:

En segundo lugar, existe otra vía posible: la hiperciudadanía, un ejercicio más profundo de la participación política que podríamos llamar ciudadanía digital, y que nos alejaría de la actitud nihilista y escéptica que caracteriza a la hiperciudadanía. Supone un ejercicio más pleno de los derechos ya consolidados, así como la promoción de nuevos derechos. La hiperciudadanía es la consecuencia de una dinámica de implantación de los derechos de cuarta generación.

Diante da complexidade dos efeitos tecnológicos, cabe pensar em uma quarta geração de direitos humanos, oriunda de uma era tecnológica pós-moderna que oferece, ao mesmo tempo, riscos e benefícios.

Tratando, pois de uma provável quarta geração de direitos humanos, Vladmir Oliveira da Silveira e Maria Mendez Rocasolano (2010, p. 182), afirmam que "é possível identificar um novo valor que concretiza a dignidade da pessoa humana para além da solidariedade: a ética, responsabilidade ou moralidade científica".

Os autores defendem a ética/responsabilidade científica como valor de proteção humana diante do atual desenvolvimento tecnológico em um sentido que ultrapassa a terceira geração de direitos humanos, ou seja, o valor solidariedade.

Considerando que os resultados da tecnologiaatingem todas as gerações de direitos humanos, vale afirmar que éimportante uma nova interpretação dos valores de liberdade, igualdade e solidariedade, com vistas a uma nova geração de direitos humanos.

Em suma, a tecnologia reúne aspectos tanto positivosquanto negativos. O lado positivo da tecnologia se concentra na capacidade de melhorar a qualidade de vida das pessoas, por essa razão esse aspecto deve serdirecionado em favor dos valores humanos. De outra parte, o lado negativo da tecnologia está intimamente ligado aopoder que quando mal direcionado representa perigo aos direitos humanos.

Esse poder contrário pode ser identificado logo na essência de meio e fim da tecnologia, pois, como meio permite o alcance de muitos objetivos, ao passo que, como fim dita o seu próprio desenvolvimento. Contudo, vale ressaltar que a tecnologia também confere poder ao seu dominador, seja este, Estado, empresa ou indivíduo.

Dessa forma, a tecnologia em si não é propriamente boa ou ruim, mas sim um poder que deve ser ordenado. Tendo em vista que os direitos humanos são conquistados para limitar o poder, cumpre admitir a importância de um processo "dinamogenesis" pós-moderno para ampliar os direitos humanos e impor limites fundados na dignidade da pessoa humana em face do poder tecnológico.

\section{CONCLUSÃO}

Diante do cenário de desenvolvimento tecnológico pós-moderno, pode-se afirmar queos novos resultados surgem em ritmo acelerado,consoante a fluidez desta era.

Revista de Direito Brasileira | São Paulo, SP | v. 13 | n. 6 | p. 231 - 248 | jan./abr. 2016 
Com o avanço da técnica que resultou na tecnologia, entendida como autossuficiente para ditar seu próprio desenvolvimento, surge uma preocupação com relação aos limitesnorteadores desse poder.

É possível considerar que na dinâmica do desenvolvimento estão também os riscos das inovações tecnológicas,pois tecnologias que podem ser consideradas de ponta em razão de propiciar diversos benefícios ao bem estar humano podem,também, ir muito além daquilo que é benéfico à natureza humana. Nesse ponto, portanto, é necessário haver uma linha limítrofe com base nos valores consagrados de direitos humanos fundamentais.

Vale considerar que, o lado positivo do desenvolvimento tecnológico deve ser protegido e fomentado, à medida que, o lado negativo deve ser combatido.

Assim, frente a essa realidadecumpre haver um diálogo entre tecnologia e direitos humanos com o objetivo de conter os excessos que ameaçam a segurança humana. Em outras palavras, importa ao ordenamento jurídico limitar o poder tecnológico quando este se apresenta ameaçador,ainda que para isso seja necessário uma nova leitura dos direitos já conquistados ou mesmo novas conquistas.

Desta feita, convém afirmar ainda que a ciência do direito pode atuar nacriação de limites ao poder tecnológico por meio de princípios que ocupam o topo do ordenamento jurídico e, dessa forma, são mais abrangentes para promover a segurança humana.

Logo, é importante que diante do poder prevaleça a dignidade da pessoa humana devidamente protegida, sendo certo que para isso será necessário a soma dos valores de liberdade, igualdade e solidariedade a uma nova perspectiva deresponsabilidade para com o próximo ecom o futuro que resultará em um desenvolvimento tecnológico seguro e a serviço das necessidades humanas.

\section{REFERÊNCIAS}

ALEXY, Robert. Teoria dos Direitos Fundamentais. Tradução de Virgílio Afonso da Silva. 2. ed. São Paulo: Malheiros Editores, 2012.

; FIGUEROA, Alfonso García. Star Trek y los Derechos Humanos. Valencia:Tirantlo Blanch, 2007.

BARCELlONA, Pietro. Il Suicidio Dell'Europa: Dalla Coscienza Infelice All'Edonismo Cognitivo. Bari: Edizioni Dedalo, 2005.

Dedalo, 2003.

. Diritto Senza Società: Dal Disincanto All'Indifferenza. Bari: Edizioni

BAUMAN, Zygmunt. Modernidade Líquida. Tradução de Plínio Dentzien. Rio de Janeiro: Zahar, 2001.

BECK, Ulrich. Sociedade de risco: Rumo a uma outra modernidade. Tradução de Sebastião Nascimento. São Paulo: Editora 34, 2010. 
La Sociedad del Riesgo Mundial: En Busca de la Seguridad Perdida. Barcelona: Paidós, 2008.

BOBBIO, Norberto. A Era dos Direitos. Tradução de Carlos Nelson Coutinho. Rio de Janeiro: Elsevier, 2004.

CABRITA, Isabel. Direitos Humanos: Um Conceito em Movimento. Coimbra: Almedina, 2011.

COMPARATO, Fábio Konder. A Afirmação Histórica dos Direitos Humanos. 5. ed. São Paulo: Saraiva, 2007.

DI CIOMMO, Francesco. Evoluzione tecnologica e regole di responsabilitá civile. Napoli: Edizioni Scientifiche Italiane, 2003.

DONAS, Javier Bustamante. Los Derechos Humanos de Cuarta Generación y sus Implicacionesenla Sociedade Contemporânea. In: Los Derechos Humanos en Internet. ; et al. Madrid: Cideal, 2012.

HESPANHA, António Manuel. Cultura Jurídica Europeia: Síntese de um Milênio. Coimbra: Almedina, 2012.

LAUREN, Paul Gordon. The Evolution of International Human Rights. Philadelphia: University of Pennsylvania, 2003.

LIPOVETSKY, Gilles. A era do vazio. Ensaios sobre o individualismo contemporâneo. Tradução de Miguel Serras Pereira e Ana Luísa Faria. Lisboa: Edições 70, 2013.

LOPEZ, Teresa Ancona. Princípio da Precaução e Evolução da Responsabilidade Civil. São Paulo: Editora QuartierLatin, 2010.

MATTEDI, Marcos Antônio. As Interpretações Sociológicas das Dinâmicas Sociais de Construção do Risco na Sociedade Moderna. Revista Grifos, Chapecó, n. 13 novembro de 2002.

PÉREZ LUÑO, Antonio Enrique. Los Derechos Humanos ante lasNuevas Tecnologias. In: NuevasTecnologías y Derechos Humanos. __. Valencia: Tirantloblanch, 2014.

2010.

Derechos Humanos, Estado de Derecho y Constitución. Madrid: Tecnos,

PIOVESAN, Flávia. Direitos Humanos e o Direito Constitucional Internacional. 13. ed. São Paulo: Saraiva, 2012.

SEVCENKO, Nicolau. A Corrida para o Século XXI - No Loop da Montanha-Russa. São Paulo: Companhia das Letras, 2001. 
SILVEIRA, Vladmir Oliveira da; ROCASOLANO, Maria Mendez. Direitos Humanos: Conceitos, Significados e Funções. São Paulo: Saraiva, 2010.

SOUSA SANTOS, Boaventura de. Pela Mão de Alice: O Social e o Político na PósModernidade. São Paulo: Cortez, 2010.

WEERAMANTRY, C.G. Os Direitos Humanos e o Progresso Científico e Tecnológico. In: Symonides, Janusz. Direitos Humanos: Novas Dimensões $e$ Desafios. Brasília: UNESCO Brasil, Secretaria Especial dos Direitos Humanos, 2003.

ZAGREBELSKY, Gustavo. Il DirittoMite. Einaudi: Torino, 2010. 